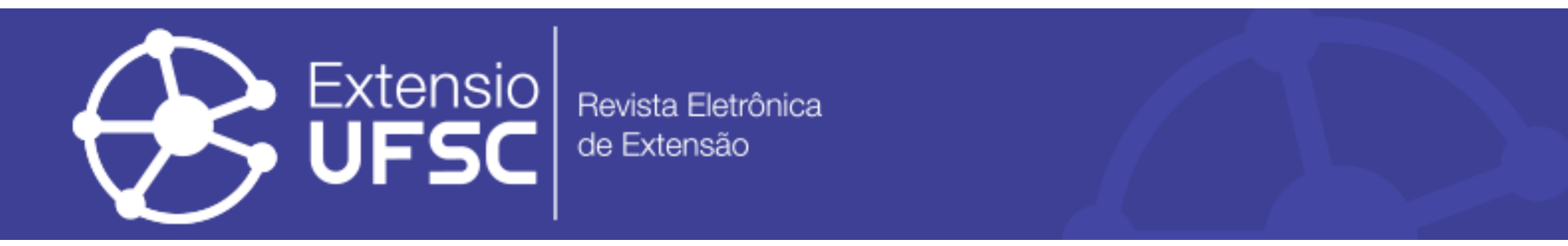

\title{
EXPERIÊNCIAS DE EXTENSÃO UNIVERSITÁRIA NA ÁREA DE ARBORIZAÇÃO DA UNIVERSIDADE FEDERAL DE GOIÁS
}

\author{
Amanda Mendonça de Oliveira \\ Universidade Federal de Goiás \\ amandamendonca61@gmail.com
}

Symone Gomes Soares Alcalá Universidade Federal de Goiás symonesoares@gmail.com

Alex Mota dos Santos Universidade Federal de Goiás alex.geotecnologias@gmail.com

\section{Resumo}

Este trabalho apresenta uma síntese dos principais resultados de experiências de extensão universitária na área de arborização do novo campus da Universidade Federal de Goiás (UFG) em Aparecida de Goiânia. A metodologia envolveu a elaboração de um mapeamento temático, a divulgação dos trabalhos e um inquérito, por meio de questionário online sobre a importância da vegetação urbana, com a comunidade universitária, discentes e docentes, e comunidade externa. Os resultados revelaram que as ações de extensão favoreceram a divulgação das atividades da UFG, incentivaram a comunicação com a comunidade externa, e possibilitaram compreender sua percepção sobre o tema em análise. Assim, a maioria dos inquiridos $(98,3 \%)$ vê a vegetação urbana como essencial para a vida humana, e principalmente, para um clima mais agradável e maior bem-estar. Além disso, 94,1\% da comunidade externa inquirida mostraram-se disponíveis a participar de projetos que incentivem o plantio de árvores em ambientes urbanos.

Palavras-chave: Paisagismo. Urbanização. Vegetação em Áreas Urbanas.

\section{UNIVERSITY EXTENSION EXPERIENCES IN THE FIELD OF AFFORESTATION OF THE FEDERAL UNIVERSITY OF GOIÁS}

\begin{abstract}
This work presents an overview of the main results of university extension experiences in the afforestation field of the new campus of the Federal University of Goiás (UFG) in Aparecida de Goiânia. The methodology has covered a thematic mapping elaboration, work dissemination to society and a survey, through an online questionnaire about the importance of urban vegetation to the university community, students and teachers, and external community. The results have revealed that the extension actions facilitated the activities dissemination of the UFG, encouraged the communication between the external community, and allowed to understand its perception about the topic under analysis. Thus, most of the respondents $(98.3 \%$ ) considers urban vegetation as something essential for the human life, and mainly, for a more pleasant climate and greater well-being. Moreover, $94.1 \%$ of the external community is interested to participate in projects that encourage the planting of trees in urban environments.
\end{abstract}

Keywords: Landscaping. Urbanization. Vegetation in Urban Areas.

\section{EXPERIENCIAS DE EXTENSIÓN UNIVERSITARIA EN EL ÁREA DE FORESTÁCION DE LA UNIVERSIDAD FEDERAL DE GOIÁS}

\begin{abstract}
Resumen
Este trabajo muestra una síntesis de los principales resultados de experiencias de extensión universitaria en el área de forestación del nuevo campus de la Universidad Federal de Goiás (UFG) en Aparecida de Goiânia. La metodología abarcó la elaboración de un mapa temático, la divulgación de los trabajos y un cuestionario online sobre la importancia de la vegetación urbana, con la comunidad universitaria, estudiantes y docentes, y comunidad externa. Los resultados revelaron que las acciones de extensión favorecerán la divulgación de las actividades de la UFG, incentivarán la comunicación con la comunidad externa, y posibilitarán la comprensión de su percepción sobre la temática de análisis. Así, la mayoría de los encuestados $(98,3 \%)$ creen que la vegetación urbana es esencial para la vida humana, y principalmente, para un clima más agradable y mayor bien estar. Adicionalmente, el $94,1 \%$ de la comunidad externa encuestada se mostró abierta a participar de proyectos que incentiven la plantación de árboles en ambientes urbanos.

Palavras clave: Paisajismo. Urbanización. Vegetación en Áreas Urbanas.
\end{abstract}




\section{INTRODUÇÃO}

A conservação e implantação de áreas verdes é uma realidade em todos os campi da Universidade Federal de Goiás (UFG), uma das maiores instituições de ensino superior do país, de modo que a partir da sua expansão, especialmente com a criação do Campus de Aparecida de Goiânia (CAP), a instituição dedica esforços, do seu quadro de pessoal em parceria com comunidade e com o poder público local para pensar e apresentar um plano de arborização.

De forma geral, um plano de arborização é um "instrumento de caráter técnico, norteador das decisões sobre quaisquer aspectos relacionados à arborização [...]” (BARCELOS et al., 2012, p. 4). Esse instrumento foi pensado e desenvolvido, pois a vegetação em áreas urbanas tem diversas funções, das quais: social, especialmente para lazer; estética, diversificação e embelezamento; psicológica, para alívio das tensões, recreação e contemplação; educação, para servir às práticas de educação ambiental; e, função ecológica, qualidade do ar, manutenção da fauna e flora (VIEIRA, 2004).

Dessa maneira, o campus UFG da cidade de Aparecida vem desenvolvendo um projeto de extensão, intitulado "Pensando Ações de Paisagismo, Arborização e Ajardinamento do Novo Campus Aparecida de Goiânia da Universidade Federal de Goiás", cujo objetivo é planejar, implementar e divulgar ações de paisagismo, arborização e ajardinamento no CAP, por meio da integração de discentes, docentes e técnicos-administrativos dos cursos de Engenharia de Produção, Engenharia de Transportes e Geologia da UFG com o poder público, a comunidade externa e profissionais que lidam com paisagismo, arborização e ajardinamento.

Segundo Lira Filho (2002, p. 7), “o paisagismo tem como objeto de trabalho a paisagem com todos os seus componentes (naturais e arquitetônicos), além da dimensão temporal”. Desse modo, essa publicação, no âmbito do projeto de extensão, enfatiza as análises na divulgação das atividades do projeto, do mapeamento da distribuição da vegetação existente na área, e da percepção das comunidades, externa e acadêmica, sobre a importância da vegetação em áreas urbanas. Para alcançar este último objetivo, foi realizada uma pesquisa por meio de questionário online, para identificar o engajamento e a percepção de ambas as comunidades sobre a importância da vegetação urbana.

O projeto de extensão busca, junto à prefeitura da cidade Aparecida de Goiânia, a recuperação das nascentes degradadas do novo CAP por meio do cercamento das nascentes e do plantio de mudas de árvores; enquanto a equipe técnica do Centro de Gestão do Espaço Físico (CEGEF) da UFG pensa a componente arquitetônica. Por outro lado, o projeto é divulgado em 
escolas do município, de forma a conscientizar sobre a importância das áreas verdes no ambiente urbano.

\section{A IMPORTÂNCIA DA VEGETAÇÃO EM ÁREAS URBANAS}

O projeto de extensão foi pensando no contexto da valorização dos espaços vegetados em áreas urbanas e que é, como referido, uma política valorizada na UFG. O novo campus desta instituição, na cidade de Aparecida de Goiânia, é resultado da política de expansão do ensino superior no Brasil.

A área do campus UFG em Aparecida de Goiânia foi doada por dois fazendeiros que possuem propriedades rurais no município, sendo que $21 \%$ dessa área são compostos por pastagens plantadas para alimento do gado bovino. Contudo, identificaram-se árvores esparsas e uma Reserva Legal que pertence aos doadores da área, mas está sob responsabilidade da UFG.

Segundo Ramos (2016), a importância da vegetação já foi definida e caracterizada na Legislação Federal, ainda na década de 60, e atualmente, de acordo com as alterações realizadas a partir do novo Código Florestal de 2012, Lei no 12.651 de 25 de maio, consta que as áreas verdes em áreas urbanas,

[...] são indisponíveis para construção de moradias, sendo destinadas aos propósitos de recreação, lazer, melhoria da qualidade ambiental urbana, proteção dos recursos hídricos, manutenção ou melhoria paisagística, proteção de bens e manifestações culturais (BRASIL, 2012, s. p.).

No contexto histórico, as áreas verdes urbanas foram implantadas a partir da prática da jardinagem no Egito e cultos religiosos na China (LOBODA e ANGELIS, 2005). Ainda segundo os autores, foi na Grécia que as áreas verdes assumiram, pela primeira vez, função pública de passeio e lazer.

Define-se área verde como área plantada que deve cumprir três funções (estética, ecológica e lazer); vegetação e solo permeável (sem laje) devem ocupar, pelo menos, 70\% da área; deve ser pública e de utilização sem regras rígidas (NUCCI, 2001, p. 198).

Estas definições possuem uma característica comum, que é de colocar a importância das áreas verdes como sendo espaços livres, permeáveis, que possuam o predomínio de vegetação independente do seu porte. 


\section{MATERIAL E MÉTODOS}

O novo campus da UFG está localizado na zona rural do município de Aparecida de Goiânia, cidade localizada ao centro-sul do estado de Goiás (Figura 1).

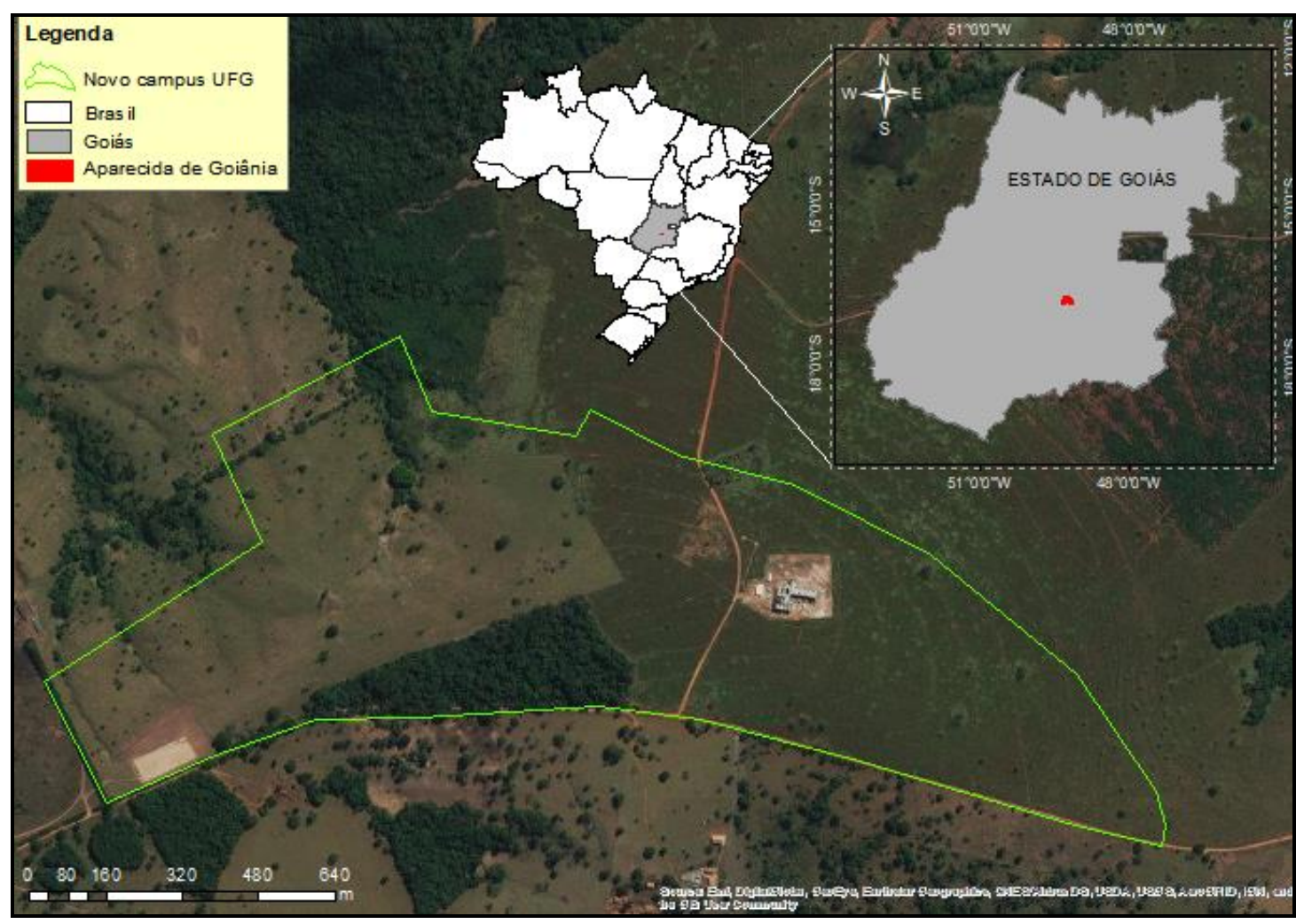

Figura 1 - Localização da obra do novo campus da UFG Aparecida de Goiânia.

Fonte: elaborada pelos autores

A área do novo campus ocupa 25 hectares, dos quais $21 \%$ são recobertos por vegetação remanescente do Cerrado. O acesso é realizado pelos bairros Montreal e Alvorada do Sul, periferia da cidade de Aparecida de Goiânia.

O processo de mapeamento básico é importante para diversos fins, pois auxilia no reconhecimento detalhado da área em estudo. Segundo Matias (1996, p. 50), nessa metodologia realizam-se "observações de uma determinada parte da realidade que lhe interessa e, usando as técnicas de mapeamento, representa por meio do uso da linguagem cartográfica as informações no mapa".

Nessa análise, métodos indiretos, a partir de um sobrevoo na área do campus foram empregados, usando um Veículo Área Não Tripulado (VANT), cedido pelo Laboratório de 
Processamento de Imagens e Geoprocessamento (LAPIG), que está vinculado ao Instituto de Estudos Socioambientais (IESA) da UFG.

A imagem foi georreferenciada no sistema World Geodetic System 1984 (WGS84) e projetada no sistema de projeção Universal Transverse de Mercator (UTM). Com a imagem georreferenciada foi realizada a digitalização sobre a imagem, dando origem a um arquivo vetorial de forma pontual com cada espécie da flora.

Após o georreferenciamento da imagem do campus, realizaram-se atividades de divulgação do projeto para as comunidades, interna e externa à universidade. Nesse sentido, o projeto foi apresentado e premiado na Feira de Ciências e Tecnologia de Aparecida de Goiânia (FECITEC), realizada nos dias 30 e 31 de outubro de 2017. Parte da equipe deste projeto realizou ainda atividades de divulgação do projeto na escola municipal de ensino fundamental Vinovita, localizada em Aparecida de Goiânia. Na mesma escola e na UFG, foi divulgado e disponibilizado um questionário online para identificar a percepção das comunidades externa e interna sobre a importância da vegetação em áreas urbanas.

Para a pesquisa estruturou-se um questionário online com seis questões fechadas e uma questão aberta relacionadas à vegetação urbana. O questionário é um instrumento de coleta de dados valioso em ensino, pesquisa e extensão, necessário para verificar se os objetivos da pesquisa foram alcançados. E nessa pesquisa a ferramenta Google Forms foi utilizada como questionário.

\section{Coleta de dados}

A coleta de dados foi realizada por meio da aplicação de um questionário online com sete questões. Posteriormente, verificou-se que um total de 136 pessoas, tanto da comunidade interna, quanto da comunidade externa, responderam ao questionário no período de 15 de dezembro de 2017 a 5 de janeiro de 2018. Como referido, o questionário tem questões relacionadas à importância da vegetação nas cidades, ao engajamento no plantio de árvores e a participação e interesse em projetos de arborização.

\section{RESULTADOS E ANÁLISES}

Os resultados da ação de extensão revelaram a integração das três dimensões constitutivas da universidade (ensino, extensão e pesquisa). A indissociabilidade dessas atividades é recomendável e não pode ser compartimentada (MOITA e ANDRADE, 2009). Ou seja, os dados coletados servirão às atividades em sala de aula, investigação científica da caracterização da 
vegetação e, para extensão, com os dados aqui apresentados. Além disso, observou que o projeto contribuiu para aproximação da universidade junto à comunidade da cidade de Aparecida de Goiânia. Isso ocorreu nas atividades interativas nas escolas visitadas, no evento onde a comunidade se encontrava e que foi realizado pela prefeitura municipal de Aparecida de Goiânia e nas visitas às instalações do novo campus da UFG. Observou ainda participação ativa do poder público municipal, como o Viveiro Municipal de Aparecida de Goiânia e a Secretaria Municipal do Meio Ambiente de Aparecida de Goiânia (SEMMA), por meio de seus servidores. Igualmente importante referir que o projeto mobilizou os técnico-administrativos, docentes e discentes da UFG em prol de um pensamento comum, conservar e revitalizar a vegetação remanescente no novo campus.

Assim, destaca-se como atividades resultantes do projeto de extensão: a) elaboração de um mapa da situação atual da vegetação no novo campus da UFG; b) a participação numa feira de ciência municipal para divulgação do projeto; c) a realização de atividades de plantio de mudas na área de uma nascente no novo campus; d) a divulgação do projeto e análise da percepção sobre a importância da vegetação em áreas urbanas numa escola municipal; e e) apresentação de resultados parciais para toda a comunidade numa mostra acadêmica, realizada no campus da Universidade Estadual de Goiás (UEG), cidade de Aparecida de Goiânia.

Do mapa, observou-se a identificação de 196 pontos que correspondem à flora, que podem ser arbustos ou árvores, isolados na área do novo CAP. A partir do arquivo vetorial criado para cada indivíduo vegetal foi adicionado um campo na tabela de atributo do Banco de Dados Geográfico (BDG). Esse produto servirá às futuras pesquisas e atividades de extensão.

A nova área do CAP foi resultado de duas doações de duas áreas de 25 hectares cada. Desse modo, uma delas está mais vegetada, pois abriga a Área de Reserva Legal de uma das propriedades rurais e que ficará sob a responsabilidade da UFG (Figura 2). Além disso, na porção noroeste mapeou-se uma nascente em que parte da vegetação da Área de Preservação Permanente (APP) foi removida e na porção nordeste mapeou-se a área de construção do novo centro de aulas da UFG. 


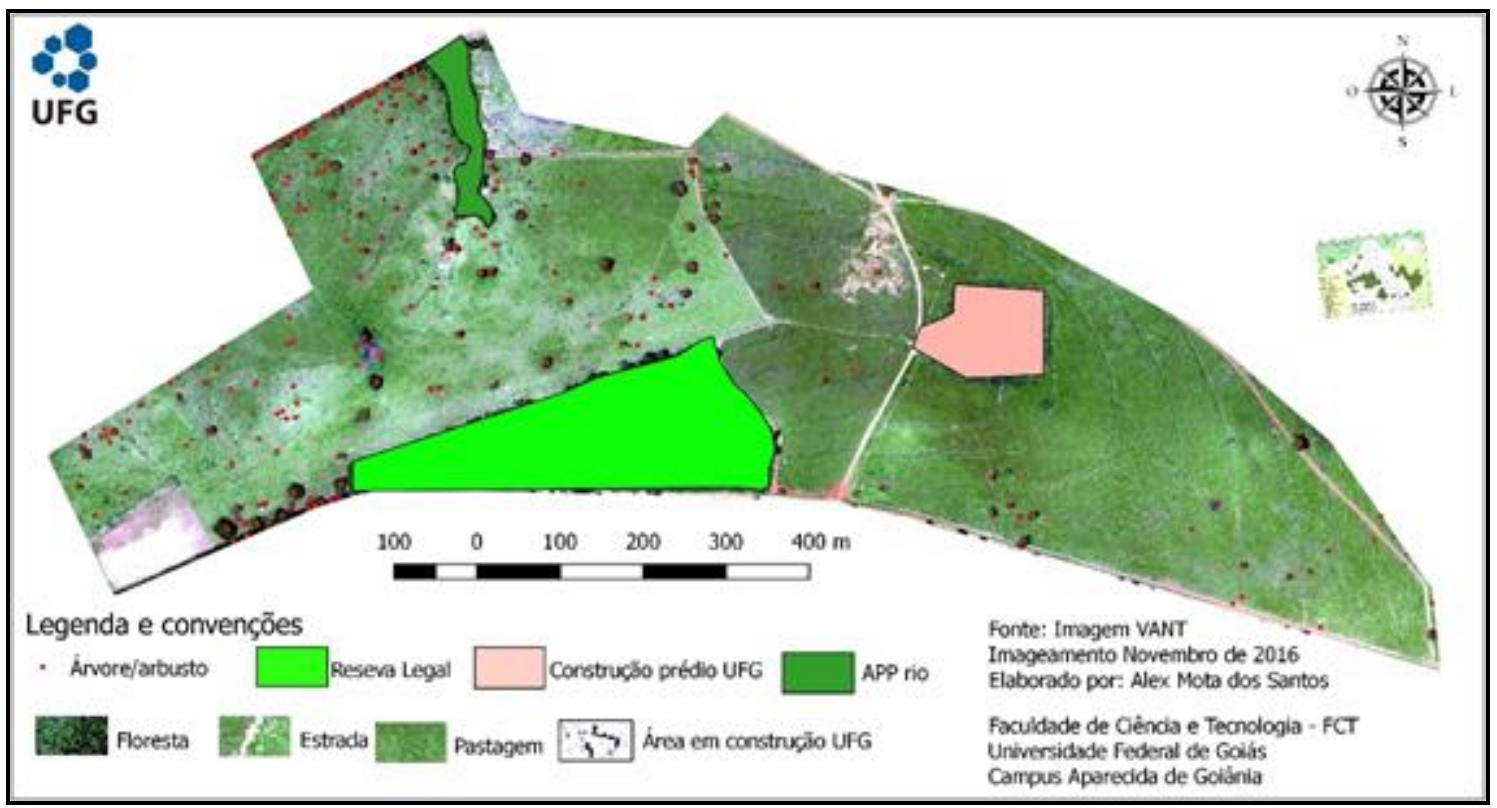

Figura 2 - Carta imagem da área do campus UFG-CAP.

Fonte: elaborada pelos autores.

Com os dados do mapeamento o grupo se apresentou na Feira de Ciência e Tecnologia de Aparecida de Goiânia (FECITEC) realizada pela prefeitura da cidade (Figura 3). Na ocasião o projeto recebeu distinção por parte da organização do evento pela sua relevância ambiental e social.

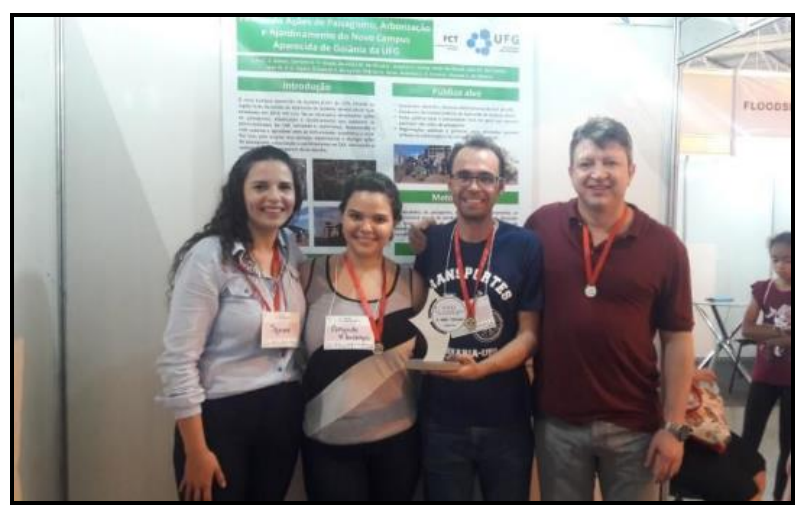

Figura 3 - Premiação do projeto na FECITEC.

Fonte: https://www.ufg.br/n/101670-alunos-e-professora-da-fct-conquistam-1-lugar-na-fecitec

A partir das atividades na área do novo CAP, observou-se que havia uma nascente e que a mesma foi parcialmente removida na APP. A partir deste ponto, a equipe do projeto de extensão, juntamente com a direção de campus da UFG e a prefeitura de Aparecida de Goiânia realizou um evento público de plantio de novas espécies. O evento foi acompanhado de estudantes da graduação, servidores da prefeitura e da UFG (Figura 4). 


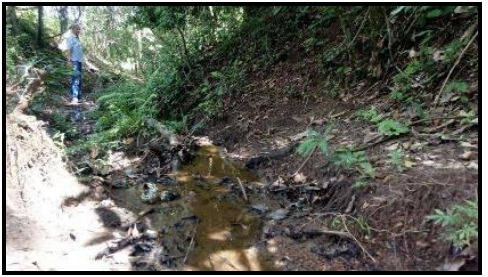

(a)

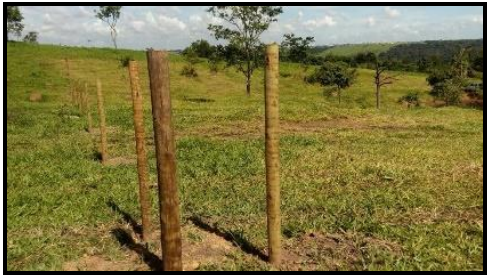

(b)

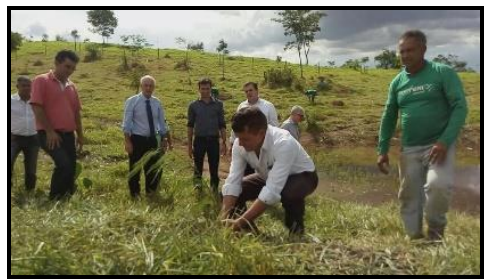

(c)

Figura 4 - Plantio de mudas na nascente do novo CAP: a) aspecto da nascente no novo CAP; b) cercamento da nascente e c) plantio de novas espécies.

Fonte: https://www.facebook.com/SemmaAparecida/

Essa atividade de requalificação dos espaços verdes é muito importante e sua divulgação leva para a comunidade a necessidade de que todos contribuam para sua a conservação. Nesse sentido, uma atividade de intervenções numa escola municipal da cidade de Aparecida de Goiânia foi realizada. Nesse momento, observou o perfil dos participantes, distribuído em três grupos (estudante da UFG, professor da UFG e comunidade externa), que mostrou prevalência de $62,5 \%$ dos participantes formados pela comunidade interna, isto é, $18,4 \%$ de professores da UFG e 44,1\% de estudantes da UFG (Figura 5). Por outro lado, 37,5\% dos participantes são formados pela comunidade externa. Esse dado não revela o engajamento dos grupos pesquisados, antes o acesso ao questionário. Isso ocorreu por que o acesso à comunidade externa é mais difícil, especialmente por que o campus atual da UFG, que funciona no prédio da Universidade Estadual de Goiás, é isolado. Por isso, recorreu-se a busca de dados num evento realizado numa escola municipal próximo ao campus da UFG.

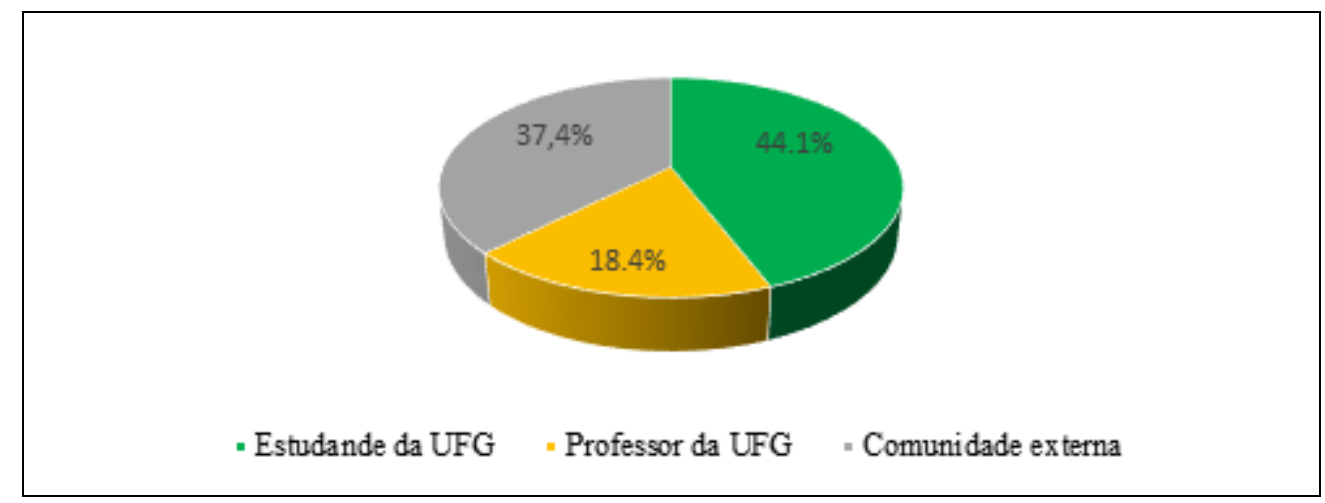

Figura 5 - Perfil dos participantes da pesquisa.

Fonte: elaborada pelos autores 
Sobre a questão que inquiriu a respeito da percepção das comunidades sobre a importância da presença de árvores nas cidades, apenas um estudante revelou que não considerava importante (1,7\%). Em pesquisas realizadas por Ribeiro (2009) e Silva e Moraes (2016) a presença da vegetação foi também considerada importante pela maioria dos inquiridos.

Ao se perguntar qual a principal importância da vegetação numa cidade, obteve-se como resultado as informações da Figura 6. A partir das respostas de ambas as comunidades, pode-se perceber que, a sombra e o clima são considerados os mais importantes numa cidade. Assim como Silva e Morais (2016) a arborização urbana é o principal fator desencadeador da necessidade de amenização do calor, por meio de um recurso natural e sustentável, o qual já é utilizado em importantes cidades do país. O trabalho de Ribeiro (2009) revelou resultados semelhantes em que sombra foi a percepção mais imediata dos inquiridos, assim também na análise de Silva e Moraes (2010). Na análise de Fedrizzi et al. (2004), os inquiridos valorizaram os aspectos cênicos da vegetação numa escola, contudo valorizaram aspectos do clima.

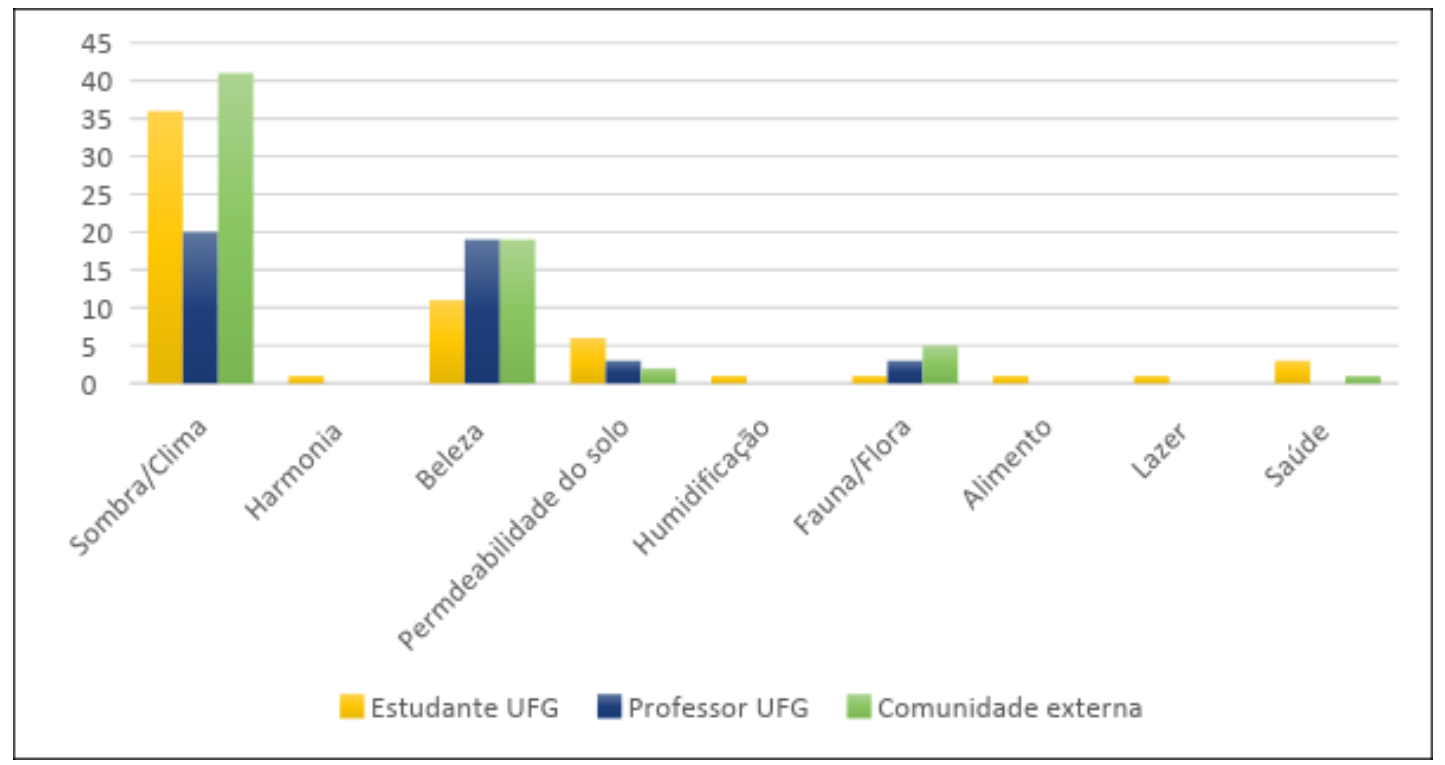

Figura 6 - Respostas à pergunta aberta: Qual a importância da vegetação numa cidade?

Fonte: elaborada pelos autores

No que respeita ao plantio de árvores em suas propriedades, observou-se que todas as comunidades inquiridas revelaram realizar tal prática (Figura 7). Contudo, foram os estudantes e a comunidade externa que informaram realizar o plantio de vegetação ornamental. Não se pode afirmar, para a amostra deste estudo,, que os professores valorizam a vegetação em suas casas como elemento de ornamentação. Além disso, foram os professores o grupo de inquiridos que mais plantou árvores nos seus quintais (56\%). 


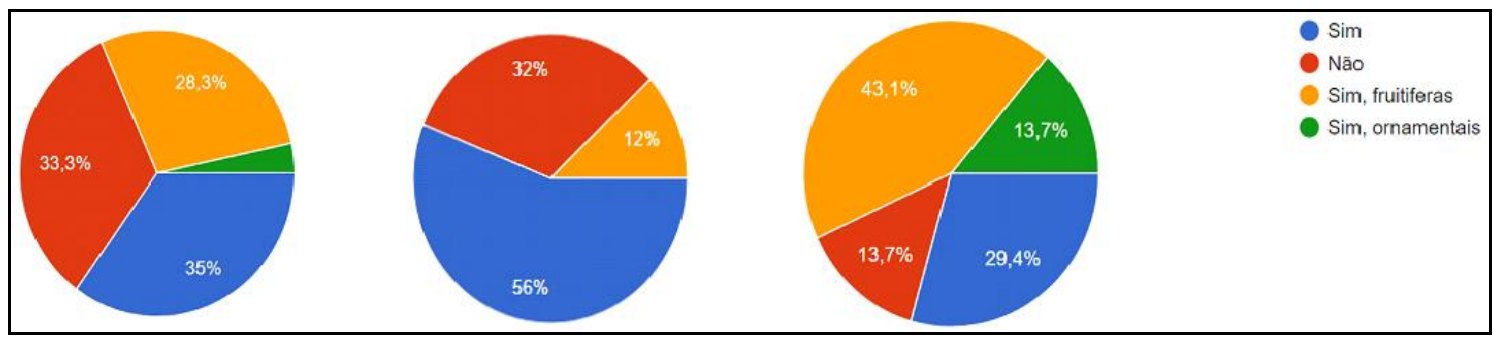

$\begin{array}{lll}\text { (a) Estudante da UFG. } & \text { (b) Professor Da UFG. } & \text { (c) Comunidade externa. }\end{array}$

Figura 7 - Respostas à pergunta: Você já plantou árvores no quintal de sua propriedade?

Fonte: elaborada pelos autores por meio do Google Forms.

Ao serem perguntados se já haviam participado em algum projeto de plantio de árvores, constatou-se que todos os grupos de inquiridos responderam positivamente, sendo que os professores $(36 \%)$ foram os que informaram terem plantado mais (Figura 8). Contudo, os alguns estudantes $(5 \%)$ e a comunidade externa $(5,9 \%)$, da amostra deste estudo, revelaram que não participaram de projeto de plantio de árvores por falta de interesse. O grupo de estudantes revelou que já realizou plantio de árvores por influência do ambiente escolar. Além disso, quase a metade dos inquiridos da comunidade externa revelou que não realizou tal atividade por falta de oportunidade. Esse resultado está de acordo com aquele obtido por Ribeiro (2009), que revelou, para uma pesquisa em Uberlândia, Minas Gerais, que 76,7\% das pessoas inquiridas contribuíram para a arborização da cidade. Ou seja, há uma recorrência de pessoas que se preocupam com o plantio de árvores em suas propriedades.

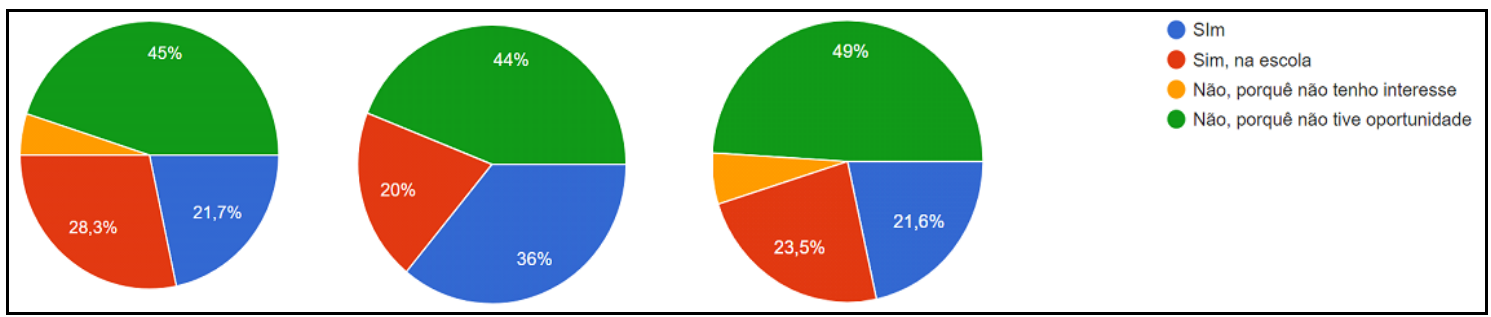

$\begin{array}{lll}\text { (a) Estudante da UFG. } & \text { (b) Professor Da UFG. } & \text { (c) Comunidade externa. }\end{array}$

Figura 8 - Respostas à pergunta: Você já participou de algum projeto de plantio de árvores? Fonte: elaborada pelos autores por meio do Google Forms.

Além disso, as comunidades interna e externa foram questionadas se teriam interesse em participar de algum projeto de incentivo ao cultivo de árvores na sua cidade, sendo que, ambas comunidades afirmaram que sim (Figura 9). Contudo, uma quantidade significativa de estudantes inquiridos $(23,7 \%)$ disse não ter interesse em participar de tais projetos. 


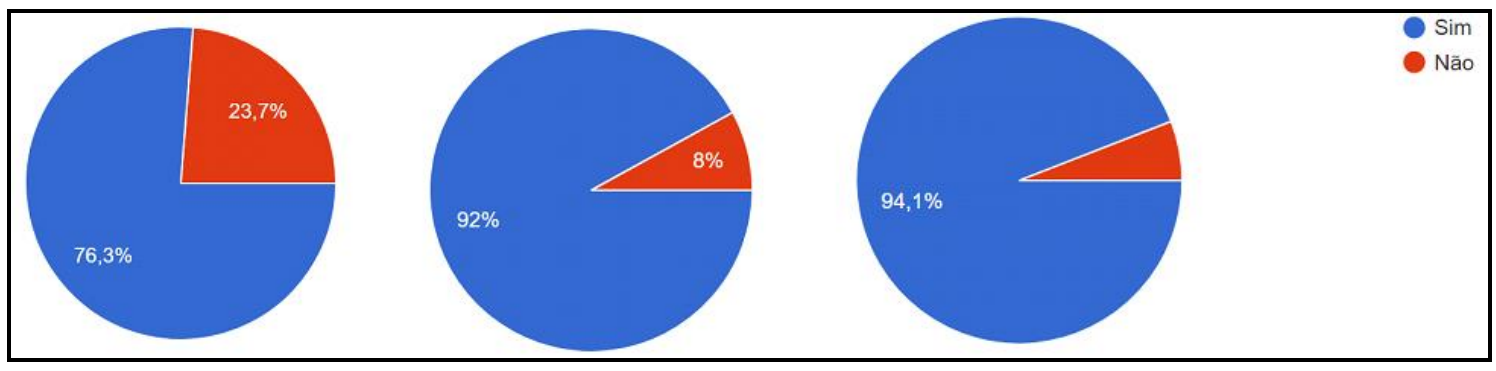

(a) Estudante da UFG.

(b) Professor Da UFG.

(c) Comunidade externa.

Figura 9 - Respostas à pergunta: Você teria interesse em participar de algum projeto de incentivo ao cultivo de árvores na sua cidade? Fonte: elaborada pelos autores por meio do Google Forms.

Além do exposto, o projeto de extensão foi estruturado na forma de uma publicação e submetido à apreciação da comissão de organização da primeira mostra acadêmica do campus da UFG de Aparecida de Goiânia (Figura 10). O trabalho foi aprovado e apresentado, onde a comunidade presente teve a oportunidade de sanar dúvidas, interagir e contribuir com os rumos futuros das atividades do projeto.

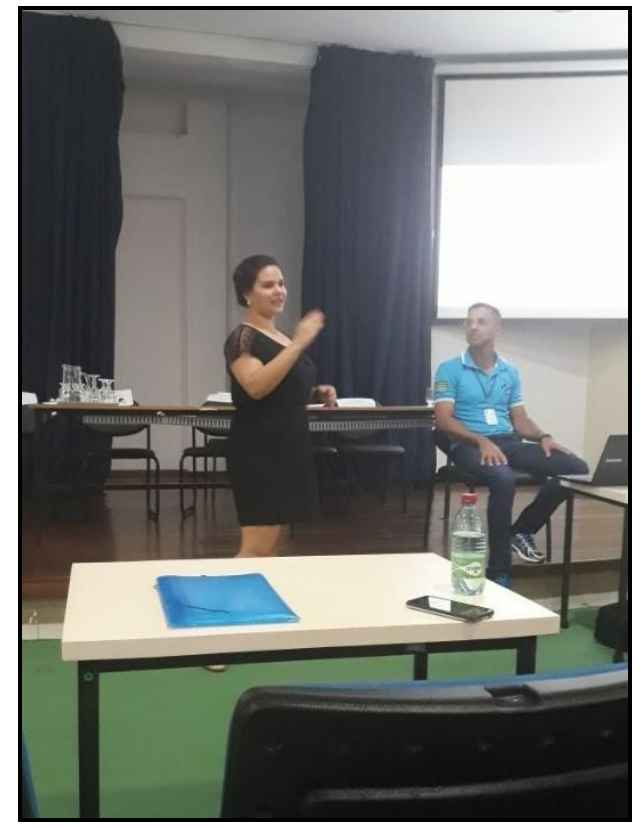

Figura 10. Apresentação de parte das ações do projeto de extensão na 1ª Mostra Acadêmica da FCT/UFG, 13/03/2018. Fonte: elaborada pelos autores

Por fim, a equipe do projeto de extensão atuou em visita à Área de Preservação Permanente (APA), Serra das Areias, uma das mais importantes áreas verdes localizadas no município de Aparecida de Goiânia. Numa próxima etapa, esforços serão destinados à conscientização da importância da referida área para a conservação das nascentes dos principais corpos hídricos que drenagem pela área urbana da cidade. 
Experiências de Extensão Universitária na área de arborização da Universidade Federal de Goiás

Assim, as atividades de divulgação e interação com a sociedade envolvente foi importante para que a UFG seja, de certa forma, apropriada e frequentada por todos. Dessa maneira, acredita-se que o projeto proporcionou o diálogo entre os diferentes autores envolvidos na implantação, consolidação de futuro e adequado funcionamento do novo campus da UFG, proporcionando, um espaço de formação e produção de conhecimento.

\section{CONSIDERAÇÕES FINAIS}

Este trabalho apresentou as principais de experiências de extensão universitária na área de arborização do novo campus da UFG na cidade de Aparecida de Goiânia, no âmbito do projeto de extensão intitulado "Pensando Ações de Paisagismo, Arborização e Ajardinamento do Novo Campus Aparecida de Goiânia da Universidade Federal de Goiás". As ações relatadas abrangeram a elaboração de um mapeamento temático, a divulgação dos trabalhos e um inquérito, por meio de questionário online sobre a importância da vegetação urbana, com a comunidade universitária e a comunidade externa.

Os resultados apontaram que as ações de extensão favoreceram a divulgação das atividades da UFG, incentivaram a comunicação e a parceria com a comunidade externa, e possibilitaram a compreensão da sua percepção sobre o tema em análise. Nesse sentido, gerou a percepção de que arborização em áreas urbanas precisa ser mais compreendido e compartilhado, a fim de favorecer a vida urbana e, promover mais ações de extensão de arborização urbana que envolvam e integrem a comunidade universitária e a comunidade externa.

\section{REFERÊNCIAS}

BARCELLOS, A. Manual para Elaboração do Plano Municipal de Arborização Urbana: Comitê de Trabalho Interinstitucional para Análise dos Planos Municipais de Arborização Urbana no Estado do Paraná (APEF, COPEL, CREA-PR, EMBRAPAFLORESTAS, IAP, EMATER, MP-PR, SANEPAR). Paraná, 2012.

BRASIL. Presidência da República. Casa Civil. Subchefia para Assuntos Jurídicos. Lei no 12.651, de 25 de maio de 2012. Novo Código Florestal. Disponível em:

<http://www.planalto.gov.br/ccivil_03/_ato2011-2014/2012/lei/112651.htm>. Acesso em: 08 mar. 2018.

FEDRIZZI, B.; TOMASINI, S.L.V.; CARDOSO, L.M. Percepção da vegetação no pátio escolar. I Conferência Latino-americana de Construção Sustentável X Encontro Nacional de Tecnologia do Ambiente Construído, 18-21 julho 2004, São Paulo. Disponível em: <ftp://ip20017719.eng.ufff.br/Public/AnaisEventosCientificos/ENTAC_2004/trabalhos/PAP0 817d.pdf>. Acesso em: 12 abr. 2018. 
Experiências de Extensão Universitária na área de arborização da Universidade Federal de Goiás

LIRA FILHO, J.A. Paisagismo: Elementos De Composição E Estética. Viçosa, MG,: Aprenda Fácil, 2002. 194p.: il. (Coleção jardinagem paisagismo. Série planejamento paisagismo; v.2)

LOBODA, C. R.; ANGELIS, B. L. D. De. Áreas Verdes Públicas Urbanas: Conceitos, Usos e Funções. Ambiência - Revista do Centro de Ciências Agrárias e Ambientais, v. 1, n. 1, p. 125 - 139, Jan/Jun. 2005.

MATIAS; L. F. Por Uma Cartografia Geográfica - Uma Análise Da Representação Gráfica Na Geografia. Universidade De São Paulo Faculdade De Filosofia, Letras E Ciências Humanas Departamento De Geografia. São Paulo 1996.

MOITA, F. M. G. S. C.; ANDRADE, F.C.A. Ensino-pesquisa-extensão: um exercício de indissociabilidade na pós-graduação. Revista Brasileira de Educação, v. 14 n. 41, p. 269-393, 2009.

NUCCI, João Carlos. Qualidade ambiental e adensamento urbano. São Paulo: Fapesp, 2001.

PARASURAMAN, A. Marketing research. 2. ed., Addison Wesley Publishing Company, p. 21 60, 1991

POLÍTICA NACIONAL DE EXTENSÃO UNIVERSITÁRIA. Fórum de Pró-Reitores de Extensão das Universidades Públicas Brasileiras - FORPROEX, Manaus, 2012. Disponível em: $<$ https://www.ufmg.br/proex/renex/images/documentos/Pol\%C3\%ADtica-Nacional-deExtens\%C3\%A3o-Universit\%C3\%A1 ria-e-book.pdf>. Acesso em: 08 mar. 2018.

RAMOS, H. F. Análise Espacial de indicadores de desenvolvimento socioambiental urbano das Regiões Norte, Noroeste e Meia Ponte do Município de Goiânia (1975 2015). 158 f. (Dissertação) Mestrado em Geografia. Universidade Federal de Goiás. Disponível em: <https://repositorio.bc.ufg.br/tede/bitstream/tede/6702/5/Disserta $\% C 3 \% A 7 \% C 3 \% A 30 \%$ 20-\%20Helci\%20Ferreira\%20Ramos\%20-\%202016.pdf>. Acesso em: 12 abr. 2018.

RIBEIRO, F. A. B. S. Arborização Urbana Em Uberlândia: Percepção Da População Revista da Católica, Uberlândia, v. 1, n. 1, p. 224-237, 2009.

SILVA, S. L.; MORAES, M. V. A. R. Percepção Ambiental E Arborização Urbana em Teresina, Piauí - Revista Equador (UFPI), Vol. 5, No 3 (Edição Especial 02), p. 320 - 339

VARES, S.F. O papel da universidade na sociedade brasileira: educação e pesquisa no ensino superior. Palestra proferida no CIEE-SP, 2012. Disponível em:

$<$ https://revistaparametro.wordpress.com/2012/03/31/o-papel-da-universidade-na-sociedadebrasileira-educacao-e-pesquisa-no-ensino-superior/> Acesso em: 12 abr. 2018.

VIEIRA, P. B. H. Uma visão geográfica das áreas verdes de Florianópolis, SC: estudo de caso do Parque Ecológico do Córrego Grande (PECG). Trabalho de Conclusão de Curso, Universidade Federal de Santa Catarina, Florianópolis - SC, 2004.

Recebido em: 23/04/2018

Aceito em: 23/11/2018 